\title{
Laparoscopic biliary and gastric bypass: a useful adjunct in the treatment of carcinoma of the
}

pancreas

\author{
M Rhodes, L Nathanson, G Fielding
}

University Department of Surgery, Royal Brisbane Hospital, Brisbane, Australia $M$ Rhodes

L Nathanson

$G$ Fielding

Correspondence to: Mr M Rhodes, Academic Department of Surgery, University Hospital of Wales, Heath Park, Cardiff.

Accepted for publication 30 August 1994
Figure 1: Laparoscopic cholecystjejunostomy and gastroenterostomy. After performing a preoperative cholangiogram, the jejunum is anastomosed to the gall bladder as illustrated.

If a gastroenterostomy is to be fashioned a second loop of jejunum is anastomosed to the stomach as

illustrated.

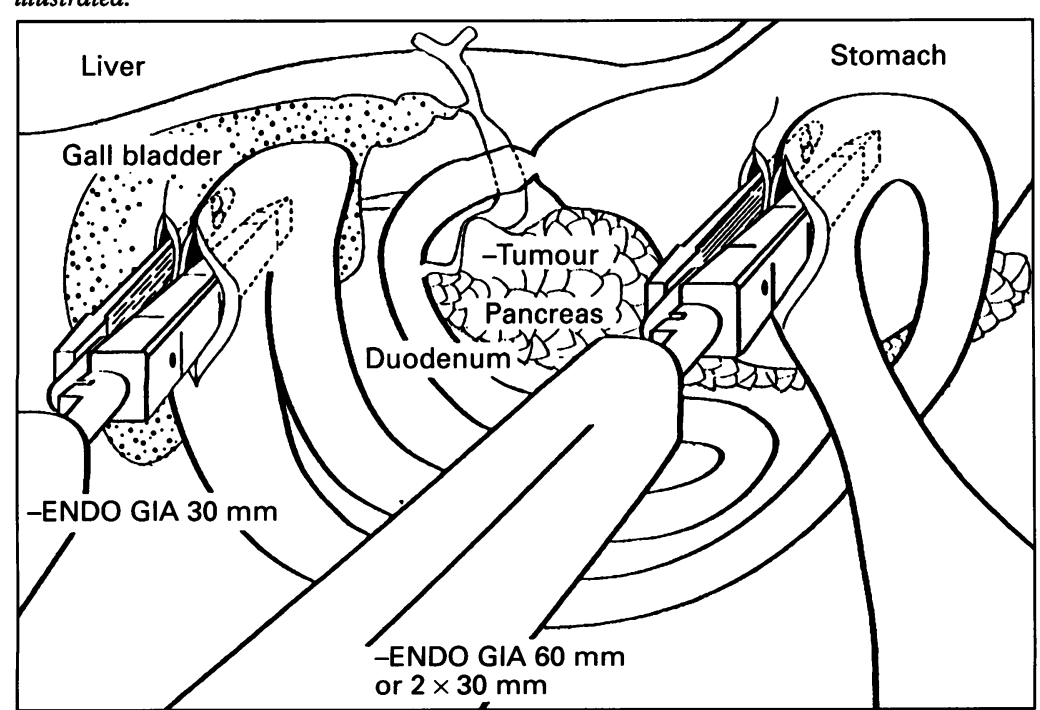
gastric emptying. Median survival in 10 patients who have died is 201 days (range 20-525). Laparoscopic biliary and gastric bypass is possible in most patients in whom endoscopic stenting has failed and in those who subsequently develop gastric outlet obstruction. Hospital stay is shorter than after open surgery and recovery more rapid.

(Gut 1995; 36: 778-780)

Keywords: pancreatic carcinoma, laparotomy, laparoscopic biliary bypass, laparoscopic gastric bypass. insertion. Treatment of the residual 10\% of patients often entails a laparotomy, which is difficult to justify when median survival of these patients is only 150 days. Laparoscopic biliary and gastric bypass offers a less invasive alternative than open surgery with shorter hospital stay and more rapid return to normal activity. Between August 1991 and March 1994, 16 patients (median age 69 years, range 31-85) had laparoscopic bypass surgery. The indications for surgery were gastric outlet obstruction at initial presentation $(n=4)$, blocked biliary stent $(n=8)$, and metastatic tumour at laparoscopy $(n=4)$. Surgery took the form of cholecystjejunostomy $(n=7)$, gastroenterostomy $(n=5)$, both procedures $(n=3)$, and failed operation $(n=1)$. Operative duration was 75 minutes (range 45-190) and hospital stay four days (range 3-33) and all apart from two patients were discharged from hospital in seven days or less. Morbidity occurred in two patients $(13 \%)$ in the form of a cerebrovascular accident and delayed

Patients

Between August 1991 and March 1994, 16 patients (age 69 years, range 31-85) have had laparoscopic biliary or gastric bypass, or both. The patients median weight was $72 \mathrm{~kg}$ (range 48-80). Indications for laparoscopic bypass were gastric outlet obstruction $(n=4)$, a blocked endoscopic stent that could not be changed $(n=8)$, and inoperability at diagnostic laparoscopy in patients for whom resection was planned $(n=4)$. Seven patients had cholecystjejunostomy, five gastroenterostomy, three both procedures, and in one case cholecystjejunostomy was not possible and the patient had laparotomy.

Operative technique (Fig 1)

Under general anaesthesia, with the patient in the supine position on an operating table suitable for peroperative cholangiography, a pneumoperitoneum is created after placement of the Hasson cannula. ${ }^{9}$ Figure 2 shows the placement of three further ports. After puncture of the gall bladder and removal of $50 \mathrm{ml}$ of 


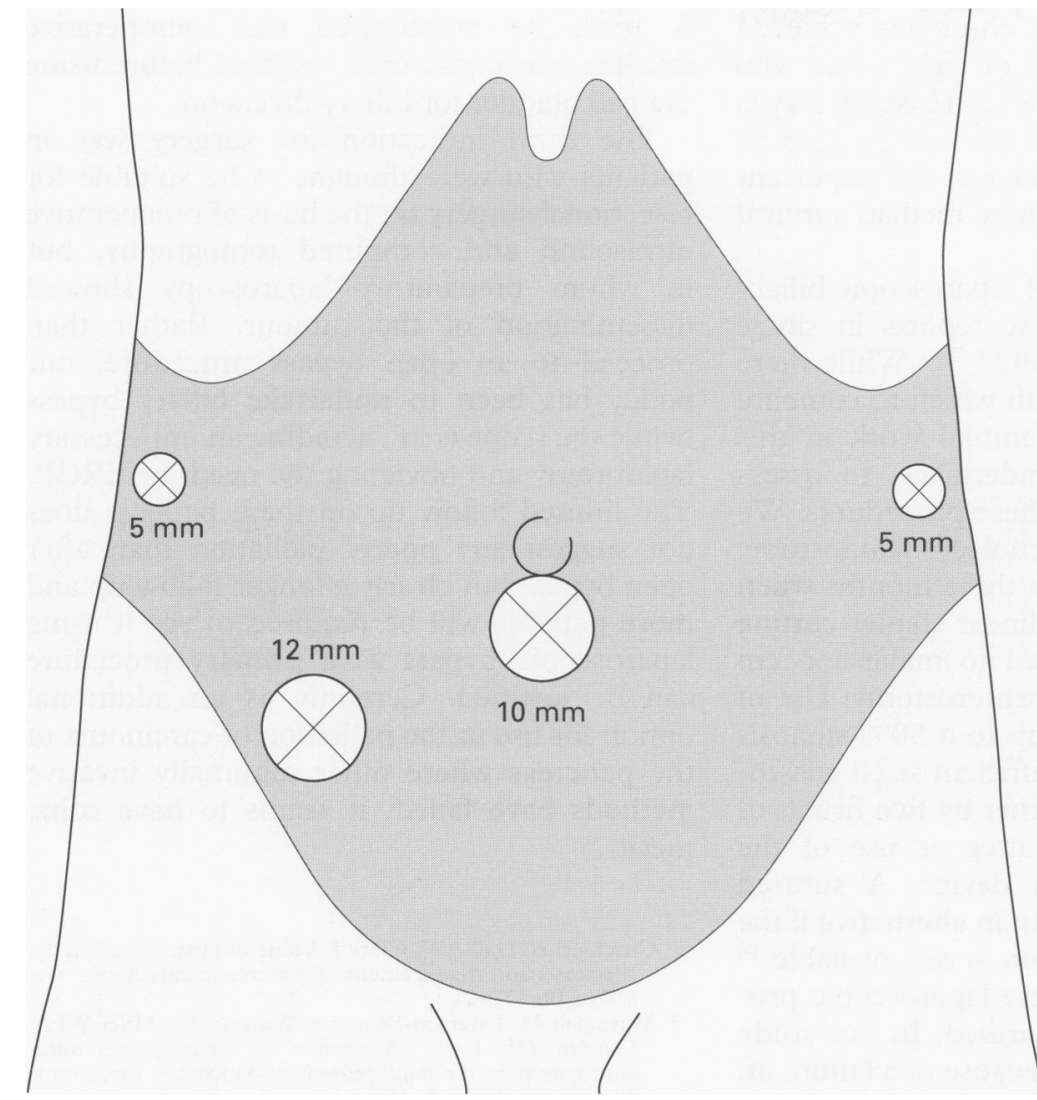

Figure 2: Operative port placement for laparoscopic cholecystjejunostomy and gastroenterostomy.

Figure 3: After puncture of the gall bladder using $a$ trochar placed in the right upper quadrant $5 \mathrm{~mm}$ operating port, $50 \mathrm{ml}$ of bile are withdrawn. Contrast is then infused into the gall bladder, and can be seen flowing into the common bile duct. The stricture caused by carcinoma of the pancreas (arrows) can be seen here $2-3 \mathrm{~cm}$ distal to the entry of the cystic duct into the main biliary tree.

\section{Patients' survival time}

\begin{tabular}{lll}
\hline Patient & Procedure & Survival (days) \\
\hline Patient & deceased & \\
1 & Cholecystjejunostomy & 267 \\
2 & Cholecystjejunostomy (converted & 525 \\
3 & to open surgery) & \\
3 & Gastroenterostomy & 138 \\
4 & Gastroenterostomy & 225 \\
5 & Cholecystjejunostomy & 75 \\
6 & Cholecystjejunostomy & 525 \\
7 & Gastroenterostomy & 177 \\
8 & Both procedures & 162 \\
9 & Cholecystjejunostomy & 272 \\
10 & Cholecystjejunostomy & 20 \\
Patient & alive as on 11 August 1994 & \\
11 & Gastroenterostomy & 229 \\
12 & Both procedures & Lost to follow up \\
13 & Cholecystjejunostomy & 161 \\
14 & Cholecystjejunostomy & 143 \\
15 & Gastroenterostomy & 139 \\
16 & Both procedures & 111 \\
\hline
\end{tabular}

All patients in this paper have been followed up by telephone call on 10 and 11 August 1994 . The next of kin have been
contacted for dates of death when patients are deceased. Patients who remain well have been contacted directly and asked about their general health and any episodes of recurrent jaundice.

choice. The deep fascia is closed in all incisions greater than $5 \mathrm{~mm}$ in size.

\section{Results}

Laparoscopic bypass was completed successfully in 15 of 16 patients $(94 \%)$. Failure to perform a laparoscopic procedure in one patient resulted from occlusion of the cystic duct by the malignant process and in this case the patient had open choledochojejunostomy. Median operating time was 75 minutes (range 45-190) and median hospital stay four days (range 3-33). Fourteen of 16 patients were discharged within seven days of surgery. Return to normal activity was complete within two weeks in these 14 patients. Two patients experienced postoperative morbidity. In one case a woman suffered a cerebrovascular accident six days after bypass and died 20 days after surgery. In a second case there was delayed gastric emptying after gastroenterostomy, which led to a 33 day hospital stay.

Median survival in 10 patients who have died is 201 days (range 20-525). Five patients remain well at the time of writing with a median follow up of 143 days (range 111-229) and a single patient has been lost to longterm follow up (Table). Telephone follow up during August 1994 shows that none of the surviving patients have experienced recurrent jaundice.

\section{Discussion}

Palliation for patients with inoperable carcinoma of the pancreas is best achieved by ERCP and placement of a biliary stent in most cases. ${ }^{11}$ Where residual problems arise because of stent blockage ${ }^{12}$ or duodenal obstruction ${ }^{13}$ or when endoscopic stenting is not possible, laparoscopic bypass may provide a useful minimally invasive treatment. Our study shows that laparoscopic bypass of both biliary and gastric obstruction is technically feasible and has a low morbidity. Successful palliation of obstructive jaundice was achieved in 10 of 11 
cases $(91 \%)$ and gastric emptying achieved within one week in seven of eight cases who had gastroenterostomy $(88 \%)$. Hospital stay is short at a median of four days and return to activity rapid; both these factors are important in a patient population where median survival time is only 150 days.

The first descriptions of laparoscopic biliary and gastric bypass as case reports in single patients were made in $1992 .{ }^{678 a}$ While there are few published data with which to compare our results, preliminary animal work in this department has been undertaken to assess longterm outcome from these procedures. We have shown that while a cholecystjejunostomy remains patent for at least three months when the surgeon uses a $3 \mathrm{~cm}$ linear stapler cutting device, it is recommended to make a $6 \mathrm{~cm}$ anastomosis for the gastroenterostomy. Use of a $3 \mathrm{~cm}$ stoma results in up to a $50 \%$ stenosis rate at three months. A sufficient sized anastomosis may be achieved either by two firings of a $3 \mathrm{~cm}$ linear stapler cutter or use of the recently produced $6 \mathrm{~cm}$ device. A sutured anastomosis can be used as an alternative if the mechanical instrumentation is not available. ${ }^{14}$

The indications for these laparoscopic procedures have yet to be clarified. In our study most patients presented because of a failure of, or complications from endoscopic treatment. In our series there have been three reasons to consider laparoscopic bypass: (a) failed stenting resulting from duodenal obstruction, (b) failed stent change, either resulting from duodenal obstruction or difficulty negotiating the biliary stricture with a guide wire, (c) peritoneal or liver metastases found at laparoscopy undertaken as a precursor to Whipple's resection.

After successful endoscopic treatment, duodenal obstruction is one indication for laparoscopic bypass. The frequency of duodenal obstruction after biliary stenting is hard to determine. Figures from medical units estimate the incidence between $5 \%$ and $7 \cdot 5 \%{ }^{13} 15$ while surgical authors often put the figure much higher at between $15 \%$ and $20 \% .1617$ Our own findings from a combined unit $^{18}$ would suggest an incidence of $5 \%$ after endoscopic stenting but $10 \%$ after open bypass surgery. Whatever the frequency of duodenal obstruction after endoscopic stenting, a laparotomy, late in the day for a patient with metastatic malignancy, is a disaster. Laparoscopic gastroenterostomy provides relief from intractable vomiting in patients with mechanical obstruction of the duodenum and allows them to return to normal activity within a fortnight.

The second important problem after biliary stenting is stent blockage. This rarely occurs because of tumour infiltration but rather is a result of bacterial growth and sludge formation. ${ }^{19}$ Because tumour progression above the endoprosthesis is rare in carcinoma of the pancreas, cholecystjejunostomy may be a useful procedure after blockage and was technically possible in all except one of our patients. Once again this avoided laparotomy and permitted rapid return to normal activity.
It must be emphasised that peroperative imaging was considered essential before using the gall bladder for biliary diversion.

The third indication for surgery was in patients who were thought to be suitable for resectional surgery on the basis of preoperative ultrasound and computed tomography, but in whom preparatory laparoscopy showed dissemination of the tumour. Rather than proceed to an open bypass procedure, our policy has been to undertake biliary bypass 'while the scope is in', avoiding an unnecessary laparotomy and obviating the need for ERCP. The limited follow up on these patients does not suggest any poorer palliation than after open bypass but clearly a longer follow up and more patients will be required to see if using laparoscopic bypass as a primary procedure can be justified. Certainly as an additional option for use in the palliation of carcinoma of the pancreas where other minimally invasive methods have failed, it seems to have some merits.

1 Cuschieri A, Hall AW, Clark J. Value of laparoscopy in the diagnosis and management of pancreatic carcinoma. Gut 1978; 19: 672-7.

2 Murugiah M, Paterson-Brown S, Windsor JA, Miles WFA, Garden OJ. Early experience of laparoscopic ultrasonography in the management of pancreatic carcinoma. Surg Endosc 1993; 7: 177-81.

3 John TG, Garden OJ. Laparoscopic ultrasonography: extending the scope of diagnostic laparoscopy. Br $\mathcal{F}$ Surg 994; 81: $5-6$.

4 Shepherd HA, Royle G, Ross AP, Diba A, Arthur M, ColinJones D. Endoscopic biliary prosthesis in the palliation of malignant obstruction of the distal common bile duct: a randomised trial. Br f Surg 1988; 75: 1166-8.

5 Andersen JR, Sarensen SM, Fruse A, Rokkjaer M, Mateen $P$. Randomised trial of endoscopic endoprosthesis versus operative bypass in malignant obstructive jaundice. Gut 1989; 30: 1132-5.

6 Dowsett JF, Russell RCG, Hatfield ARW, Cotton PB, Speer AG, Houghton J, et al. Malignant obstructive jaundice: what is the best management? A prospective randomised trial of surgery versus endoscopic stenting. Gut 1988; 29: A1493.

7 Shimi S, Banting S, Cuschieri A. Laparoscopy in the management of pancreatic cancer: endoscopic cholecystjejunostomy for advanced disease. Br $\mathcal{F}$ Surg 1992; 74: 317-9.

8 Fletcher DR, Jones RM. Laparoscopic cholecystjejunostomy as palliation for obstructive jaundice in inoperable carcinoma of the pancreas. Surg Endosc 1992; 6: 147-9.

8a Wilson RG, Varma JS. Laparoscopic gastroenterostomy for malignant duodenal obstruction. Br ₹ Surg 1992; 79: 1348 .

9 Hasson HM. Window for open laparoscopy. Am 7 Obstet Gynecol 1980; 137: 869-70.

10 Nathanson LK. Laparoscopy and pancreatic cancer: biopsy, staging and bypass. Ballieres Clin Gastroenterol 1993; 7 : 941-60.

11 Cotton PB. Nonsurgical palliation of jaundice in pancreatic cancer. Surg Clin N Am 1989; 69: 613-27.

12 Speer AG, Cotton PB, MacRae KD. Endoscopic management of malignant biliary obstruction: stents of $10 \mathrm{FG}$ are preferable to stents of 8 FG. Gastrointest Endosc 1988; 34: 412-7.

13 Speer AG, Cotton PB. Endoscopic treatment of pancreatic cancer. Int $\mathcal{F}$ Pancreatol 1988; 3: S147-58,

14 Nathanson LK. Laparoscopic gastroenterostomy. In: Rob E Smiths surgery of the upper gastrointestinal tract. London: Smiths surgery of the upper gastrot
Chapman Hall, 1994: 575-83.

15 Tytgat GNJ, Bartelsman JF, Den Hartog Jaeger FCA Huibregtse K, Mathus-Vliegen EMH. Upper intestinal and biliary tract endoprostheses. Dig Dis Sci 1986; 31 $57 \mathrm{~S}-76 \mathrm{~S}$

16 Sarr MG, Cameron JL. Surgical management of unresectable carcinoma of the pancreas. Surgery 1982; 91: 123-33.

17 Watanapa P, Williamson RCN. Surgical palliation for pancreatic cancer: developments during the past two decades. Br F Surg 1992; 79: 8-20.

18 Armitage E, Rhodes M, Puntis M, Lawrie B. Endoscopic management for jaundice caused by carcinoma of the pancreas. Gastroenterology 1994; 106: A284.

19 Speer AG, Cotton PB, Rode J, Seddon AM, Neal CR Holton $\mathrm{J}$, et al. Biliary stent blockage with bacterial biofilm. Ann Intern Med 1988; 108: 546-53. 